\title{
RESEARCH
}

Open Access

\section{Management of medical emergencies in orthodontic practice}

\author{
M. Amiri Bavandpour, C. Livas and R. E. G. Jonkman
}

\begin{abstract}
Background: The aims of this study were to survey the occurrence of acute medical situations in Dutch orthodontic practice and to examine the self-perceived competence of orthodontists in managing acute medical emergencies.

Methods: A self-designed questionnaire was distributed among all 149 Dutch orthodontists attending the spring meeting of the Dutch Society for Orthodontists. The questionnaire was divided into three parts, addressing background information of the orthodontist, precautions against and experiences in acute medical situations, and self-perceived competence of nine common medical emergencies. The statistical analysis was performed using the chi-square test and a multiple logistic regression analysis.

Results: The response rate was $74.5 \%$ (105 out of 149). The male to female ratio in this population was 55:50. Mean age of all participants was 46.9 years (SD 10.4 years) with on average 16.7 years of working experience (SD 10.6 years). The most common medical emergency reported by Dutch orthodontists was vasovagal collapse $(n=219)$, followed by acute allergic reaction $(n=163)$ and hyperventilation $(n=83)$. On average, $75 \%(n=79)$ of the orthodontists felt competent to handle any acute medical situation with an average occurrence of 0.36 acute medical emergencies per orthodontist per year. Male participants were more likely to send patients towards the emergency department $(p=0.049)$. Moreover, a statistically significant negative correlation was observed between self-perceived competence handling hypoglycemia and years of clinical experience. The longer orthodontists were clinically active, the less competent they felt when encountered with a hypoglycemia $(p=0.031)$.
\end{abstract}

Conclusions: Medical emergencies may be rare but challenging occurrences in the orthodontic practice. It is strongly recommended for all orthodontists and supporting staff to be trained regularly in the management of medical emergencies and to possess up-to-date evidence-based knowledge. Familiarity with and availability of appropriate drugs and equipment are deemed essential to the management of acute medical emergencies that may arise in the orthodontic practice.

Keywords: Medical emergencies, Orthodontic practice management, Continuing professional education, Selfperception, Survey

\footnotetext{
* Correspondence: m.amiribavandpour@acta.nl

Department of Orthodontics, Academic Center for Dentistry Amsterdam

(ACTA), University of Amsterdam and VU University Amsterdam, Amsterdam,

The Netherlands
} 


\section{Background}

Nowadays, patient safety and risk management have become a priority in dental and orthodontic practice. In Japan, 19 to $44 \%$ of the dentists experience a medical emergency in each year with the vast majority of complications occurring between patients from the age of 20 to 49 years of age [1]. A Dutch study reported an occurrence of 0.75 medical emergencies per dentist per year [2]. In a scoping review on medical emergencies in dental practice, it is reported that 43.6 to $75 \%$ of dentists will be required to perform some form of medical emergency management throughout their career [3]. Although life-threatening medical emergencies are rare in dental practice, according to Collange et al., approximately $5 \%$ of general practitioners have to cope with cardiopulmonary resuscitation (CPR) at least once during their career [4]. Members of the dental and orthodontic team are expected to adequately manage common acute medical emergencies that might occur. Nevertheless, dentists still lack skills for managing medical emergencies regardless of the incorporation of medical training into dental curricula $[3,5,6]$. Moreover, only $69 \%$ of dentists feel comfortable managing medical emergencies in a dental setting [7].

While orthodontic services have traditionally been provided to children, adolescents, and young adults, over the past few decades the population in orthodontic practice has been changing. Increasing numbers of adults are choosing orthodontic treatment $[8,9]$. An older population results in more medically compromised patients due to chronic medical conditions and increased usage of long-term medication [10-14]. With the increased number of medically compromised individuals, it is imperative that orthodontists are able to manage medical emergencies [7]. The key finding of the scoping review of Vaughan et al. [3] is that there is a lack of preparedness towards medical emergencies, despite a universal recognition of the importance and desire to improve medical skills. While serious or major medical emergencies are not common in dental or orthodontic practices, being prepared to manage a medical emergency is critical, as it may in fact be life-saving [7].

To the best of the authors' knowledge and according to the literature, no studies have been conducted on the occurrence of medical emergencies and orthodontists' competence to cope with medical emergencies in orthodontic practice in the Netherlands. The aim of this study was to determine the occurrence of common acute medical situations within Dutch orthodontic practice and to determine the self-perceived competence of Dutch orthodontists to act adequately when encountered with certain acute medical situations.

\section{Methods}

This survey was conducted during the Annual Spring Meeting of the Dutch Society of Orthodontists (NVvO
[Nederlandse Vereniging van Orthodontisten]). At this meeting, held on the 28th and 29th of March 2019 in Soestduinen, Utrecht, the Netherlands, a questionnaire was handed out to all present orthodontists $(N=149)$. One month prior to the meeting, all participating members were informed about the research and its objectives via e-mail. The survey instrument was pre-tested and partially based on the questionnaire used by van Diermen et al. [15]. All questions were structured in a closed answer format. The questionnaire consisted of three parts. The first part addressed background information of the orthodontists including age, gender, years of practice, working affiliation, and origin of specialty training. The second part consisted of nine closed-ended questions regarding precautions against general acute medical situations and experiences in their orthodontic practice. The third part of the questionnaire was based on nine common medical emergencies seen in Dental practice, which included vasovagal collapse, hyperventilation, angina pectoris (AP), myocardial infarct (MI), cardiac arrest, aspiration, asthma, hypoglycemia, epilepsy, and an acute allergic reaction [16-18]. For all kind of emergencies, questions were asked about the occurrence of the emergency and about their self-perceived competence handling these acute medical situations when encountered in the orthodontic practice. Incomplete questionnaires and questionnaires from clinically inactive orthodontists were excluded from analysis.

\section{Statistical analysis}

Statistical Package for Social Sciences version 25.0 and was used for data analysis. Means and standard deviations were used for descriptive statistics of all continuous variables. The chi-square test was used for 2-by-2 cross tables, and when necessary, the Fisher exact test was applied. Multiple logistic regression analysis was conducted. A significance level of $\alpha=0.05$ was used for all tests.

\section{Results}

Of all questionnaires handed out, 111 were returned anonymously (response rate $74.5 \%$ ). Five orthodontists did not fill in the questionnaire completely, and one orthodontist was not clinically active. The data on which the analysis was performed is based on the remaining 105 fully completed questionnaires. The male to female ratio of the population was 55:50 (52.4\% male). Mean age of all participants was 46.9 years (SD 10.4 years) within the range of 31 to 72 years (all clinically active). The average years of working experience was 16.7 years (SD 10.6 years), ranging from 2 to 41 years of experience. Table 1 gives an overview by gender of age, years of professional experience, place of postgraduate training, and 
Table 1 Sample characteristics

\begin{tabular}{|c|c|c|c|c|c|c|c|c|}
\hline \multirow{2}{*}{$\begin{array}{l}\text { Study sample } \\
n=105\end{array}$} & \multicolumn{4}{|c|}{ Male, $n=55(52.4 \%)$} & \multicolumn{4}{|c|}{ Female, $n=50(47.6 \%)$} \\
\hline & Mean & SD & Min. & Max. & Mean & SD & Min. & Max. \\
\hline Age (y) & 50.6 & 10.1 & 31 & 72 & 42.7 & 9.1 & 31 & 61 \\
\hline Experience (y) & 20.0 & 10.9 & 3 & 41 & 13.1 & 9.0 & 2 & 33 \\
\hline \multicolumn{2}{|l|}{ Professional setting } & \multicolumn{3}{|c|}{ Male, $n(\%)$} & & \multicolumn{3}{|c|}{ Female, $n$ (\%) } \\
\hline \multicolumn{2}{|l|}{ Practice owner } & & \multicolumn{2}{|c|}{$40(72.7 \%)$} & & \multicolumn{2}{|c|}{$26(52 \%)$} & \\
\hline \multicolumn{2}{|l|}{ Practice owner and locum } & \multicolumn{3}{|c|}{$1(1.8 \%)$} & & \multicolumn{2}{|c|}{$2(4 \%)$} & \\
\hline \multicolumn{2}{|l|}{ Practice owner and academic } & \multicolumn{3}{|c|}{$4(7.2 \%)$} & & \multicolumn{2}{|c|}{$3(6 \%)$} & \\
\hline \multicolumn{2}{|l|}{ Locum } & \multicolumn{3}{|c|}{$8(14.5 \%)$} & & \multicolumn{2}{|c|}{$18(36 \%)$} & \\
\hline \multicolumn{2}{|l|}{ Locum and academic } & \multicolumn{3}{|c|}{$1(1.8 \%)$} & & \multicolumn{2}{|l|}{0} & \\
\hline \multicolumn{2}{|l|}{ Academic } & \multicolumn{3}{|c|}{$1(1.8 \%)$} & & \multicolumn{2}{|c|}{$1(2 \%)$} & \\
\hline \multicolumn{2}{|l|}{ Orthodontic training location } & \multicolumn{3}{|c|}{ Male, $n(\%)$} & & \multicolumn{2}{|c|}{ Female, $n(\%)$} & \\
\hline \multicolumn{2}{|l|}{ Amsterdam } & \multicolumn{3}{|c|}{$16(29.1 \%)$} & & \multicolumn{2}{|c|}{$21(42 \%)$} & \\
\hline \multicolumn{2}{|l|}{ Nijmegen } & \multicolumn{3}{|c|}{$12(21.8 \%)$} & & \multicolumn{2}{|c|}{$13(26 \%)$} & \\
\hline \multicolumn{2}{|l|}{ Groningen } & \multicolumn{3}{|c|}{$7(12.7 \%)$} & & \multicolumn{2}{|c|}{$7(14 \%)$} & \\
\hline \multicolumn{2}{|l|}{ Abroad } & $20(3$ & & & & $9(1$ & & \\
\hline
\end{tabular}

Overview of sample size, age, years of experience, professional setting, and where the training of the orthodontists is by gender $y$ years

professional setting. Almost one third of all participants $(n=29 / 27.6 \%)$ was trained abroad.

Figure 1 shows the second part of the questionnaire regarding precautions against acute medical situations and past experiences with acute medical situations in orthodontic practice. Of all orthodontists, $97.1 \%$ takes a medical history before treatment and $70.5 \%$ repeats a medical history at least once a year for each patient. In $88.6 \%$ of the orthodontic practices, a medical emergency kit is present. When present, $82.9 \%$ of the orthodontists knew how to use it. In 39\% of the practices, an AED
(Automatic External Defibrillator) was present. Although only present in about one third of the practices, $79.0 \%$ of the participants knew how to use it. Furthermore, 61.0\% of the orthodontists were CPR trained. Finally, approximately one in four orthodontists $(23.8 \%)$ has discontinued treatment because of an acute medical situation at least once during their career. An even smaller number, $15.2 \%$ of all orthodontists have called the emergency line and/or have sent a patient to the emergency department of the hospital at least once during their career. For all questions, no statistical difference was found between

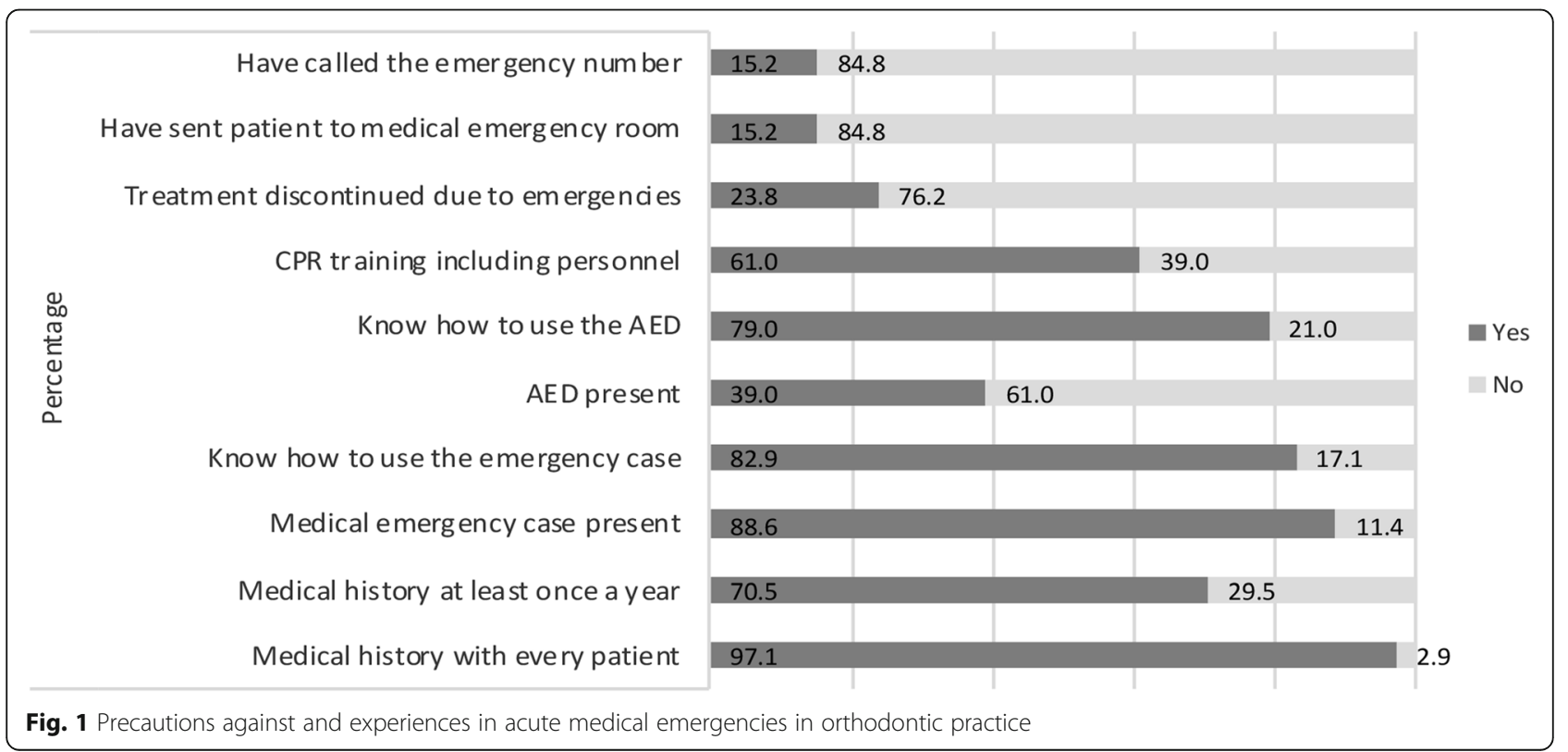


Table 2 Experience and perceived competence with common medical emergencies

\begin{tabular}{lllll}
\hline & Experience & Competence & Total occurrence & Occurrence per orthodontist per year \\
\hline Vasovagal collapse & $69.5 \%$ & $87.6 \%$ & 219 & 0.125 \\
Hyperventilation & $36.2 \%$ & $94.3 \%$ & 83 & 0.047 \\
AP/Ml & $4.8 \%$ & $53.3 \%$ & 5 & 0.003 \\
Cardiac arrest & $0.0 \%$ & $76.2 \%$ & 0,0 & 0,000 \\
Aspiration & $20.0 \%$ & $70.5 \%$ & 27 & 0.015 \\
Asthma & $4.8 \%$ & $56.2 \%$ & 12 & 0.007 \\
Hypoglycemia & $26.7 \%$ & $76.2 \%$ & 64 & 0.036 \\
Epileptic insult & $25.7 \%$ & $84.8 \%$ & 50 & 0.028 \\
Allergic reaction & $31.4 \%$ & $76.2 \%$ & 163 & 0.093 \\
Total/average & & $75.0 \%$ & 573 & 0,355 \\
\hline
\end{tabular}

Percentages of orthodontists that experienced an acute medical situation (Experience) and that felt competent to handle a specific acute medical situation (Competence) are displayed. Total occurrence describes the number of medical emergencies that occurred during the career of all 106 orthodontists with a total of 1786 years of experience, resulting in an occurrence per orthodontist per year

the male and female participants (data not shown), except for the last question $(p=0.049)$. Male participants of the study have sent patients towards the emergency department of the hospital more often than the female participants (male-to-female ratio $=12: 4$ ).

Orthodontists' experience with acute medical situations and their self-perceived competence is displayed in Table 2. On average, $75 \%$ of the orthodontists felt competent to handle any acute medical situation with an average occurrence of 0.36 acute medical emergencies per orthodontist per year. Furthermore, in most cases when an orthodontist had encountered an acute medical situation in the past, he or she felt more competent to handle this situation in the future. A statistically significant correlation was observed for aspiration $(p=0.025)$, asthmatic attack $(p=0.043)$, hypoglycemia $(p=0.001)$, epileptic attack $(p=0.011)$, and allergic reaction $(p=$ 0.058). In case of an ischemic heart disease, the opposite was true. Orthodontists exposed to this acute medical situation felt less competent compared to orthodontists who had never encountered such an incident $(p=$ 0.375). A cardiac arrest was never encountered in clinical practice by any of the orthodontists included in this study.

Table 3 displays results from the multiple logistic regression analysis. A positive correlation was observed between self-perceived competence handling an aspiration and orthodontic training location. Orthodontists trained in Nijmegen felt more competent to act in case of an aspiration compared to orthodontists trained in Amsterdam $(p=0.023)$. A statistically significant negative correlation was observed between self-perceived competence handling hypoglycemia and years of clinical experience. The longer the orthodontists were clinically active, the less competent they felt when encountered with a hypoglycemia $(p=0.031)$. A tendency was observed in which women were less likely to feel competent in case of a hypoglycemia compared to men. This was also true for orthodontists trained in Groningen or abroad compared to orthodontists trained in Amsterdam. Although these correlations were not significant, a tendency was also observed in which women felt less competent compared to men in handling epilepsy $(p=0.065)$. Finally, a positive correlation tendency

Table 3 Multiple logistic regression analysis was performed for all acute medical situations and the following predicting variables: sex, years clinically active, and training location

\begin{tabular}{lllllllll}
\hline Acute medical situation & Predicting variable & Coefficient & Standard error & Wald's $\boldsymbol{X} \mathbf{2}$ & $\mathbf{d f}$ & $\boldsymbol{P}$ value & Odds ratio & Odds ratio 95\% Cl \\
\hline Epilepsy & Women & -1.179 & 0.639 & 3.407 & 1 & 0.065 & 0.308 & $0.088-1.076$ \\
Allergic reaction & Nijmegen & 1.251 & 0.717 & 3.407 & 1 & 0.081 & 3.494 & $0.858-14.236$ \\
Diabetes & Women & -1.079 & 0.556 & 3.769 & 1 & 0.052 & 0.340 & $0.114-1.010$ \\
& Active years & -0.055 & 0.026 & 4.628 & 1 & $\mathbf{0 . 0 3 1}$ & 0.946 & $0.900-0.995$ \\
& Groningen & -1.518 & 0.784 & 3.745 & 1 & 0.053 & 0.219 & $0.047-1.020$ \\
Aspiration & Abroad & -1.131 & 0.645 & 3.073 & 1 & 0.080 & 0.323 & $0.091-1.143$ \\
Vasovagal collapse & Nijmegen & 1.605 & 0.705 & 5.179 & 1 & $\mathbf{0 . 0 2 3}$ & 4.980 & $1.250-19.847$ \\
\hline A signfive years & 0.076 & 0.042 & 3.274 & 1 & 0.070 & 1.078 & $0.994-1.170$ \\
\hline
\end{tabular}

A significance level of $a=0.05$ was used 
was observed for self-perceived competence in handling vasovagal collapse and years of clinical experience. The longer the orthodontists were clinically active, the more competent they felt in handling a vasovagal collapse, although not statistically significant $(p=0.070)$.

\section{Discussion}

Although medical emergencies might be rare, they are definitely challenging in the orthodontic practice. Having a medical history taken by orthodontists is an important step in preparing for a possible medical emergency and gives a better chance in preventing it [19]. In our study, 97.1\% of all orthodontists take a medical history with every patient, which is outstanding though not perfect, as still $2.9 \%$ does not. Moreover, only $70.5 \%$ of the orthodontists update the medical history every year, which causes concern. It is absolutely indispensable to keep the medical history up to date. An updated medical history is of absolute necessity, and failing to obtain it is considered negligence of duty [19]. Moreover, in the Netherlands, orthodontists have an obligation to update the medical history annually in context of five annual reregistration [20].

A rather high percentage (88.6\%) of the orthodontic practices has a medical emergency kit present, and $82.9 \%$ of the orthodontists also know how to use it. This is comparable to other studies where similar percentages have been reported $[6,19]$. Also, the presence of a medical emergency kit is obligatory in regard to legal reregistration. This contradicts with the fact that in only $39 \%$ of the practices an AED was present, which is a very low percentage, though a rather high percentage of the orthodontists (79\%) knew how to use it. Of the questioned orthodontists in this study $76.2 \%$ perceived themselves to be competent handling a cardiac arrest although only $61 \%$ of the questioned orthodontists were CPR trained. Al-Iryani et al. [19] reported that 95\% of the questioned practitioners were trained in basic life support. Alhamad et al. [21] and Arsati et al. [22] reported that respectively $44.8 \%$ and $43 \%$ were skilled in performing CPR. It is at least remarkable that many orthodontists prepare themselves for handling a cardiac arrest, although cardiac arrest was never encountered by any of the participants. This contradicts with the article of Collange et al. [4] which reported that $5 \%$ of general dental practitioners will be confronted with CPR in clinical dental setting. Nevertheless, orthodontists should be trained in CPR, but also in handling less severe and more frequently occurring medical emergencies.

In this study, the most common medical emergency reported by Dutch orthodontists was vasovagal collapse, which is consistent with other studies [1, 22-26]. In contrast with literature, acute allergic reaction was the second most commonly reported emergency in our study, whereas in other studies hyperventilation, hypoglycemia and epileptic insult are reported as the second most common emergencies $[1,3,21]$. The third most reported medical emergency was hyperventilation. A minor part (4.8\%) of the orthodontists encountered angina pectoris and/or a myocardial infarct. However, approximately one quarter of the orthodontists had witnessed aspiration, hypoglycemia, and an epileptic insult. It is therefore of absolute necessity that orthodontists are sufficiently trained in managing these medical emergencies.

Finally, self-perceived competence in handling acute medical situations was also evaluated in this study. Percentages ranged from $53.3 \%$ in case of angina pectoris and/ or myocardial infarction to $94.3 \%$ in case of hyperventilation. On average, $75 \%$ of the orthodontists felt competent to handle acute medical situations in orthodontic practice, which is a rather high percentage compared to literature [19]. However, still one quarter of the orthodontists, which is a considerable part, feel themselves incompetent in handling medical emergencies in orthodontic practice. It appeared that orthodontists felt more competent when he or she had been exposed to the medical emergency in the past. This information pledges for practical training. After all, when exposed to medical emergencies, in daily practice or in simulated training circumstances, orthodontists will consider themselves more competent. For ischemic heart diseases, the opposite was true, indicating possible difficulties when being confronted with this particular acute medical situation.

Interestingly, orthodontists trained in Nijmegen felt more competent to act in case of an aspiration, and orthodontists trained in Groningen or abroad were less likely to feel competent in case of a hypoglycemia compared to orthodontists trained in Amsterdam. A difference in medical training during the orthodontic traineeship may underlie this difference. Furthermore, the longer the orthodontists were clinically active, the less competent they felt when encountered with a hypoglycemia. Therefore, one might think that older orthodontists did not keep their medical knowledge up to date during their career. Although not significant, the opposite was true for vasovagal collapse, in which the longer the orthodontists were clinically active, the more competent they felt in handling a vasovagal collapse. Vasovagal collapse was the most frequently occurring acute situation in daily practice and is relatively easy to handle. Finally, a tendency was observed in which women were less likely to feel competent in case of a hypoglycemia and epilepsy compared to men (both not significant). This tendency might be explained by the difference between men and women, in which men consistently report higher self-esteem and confidence than women [27]. 
To the authors' knowledge, this is the first study that reports on occurrence of medical emergencies in the orthodontic practice in the Netherlands. A strength of the study is the relatively high response rate calculated as a percentage of all registered orthodontists in the Netherlands (33.9\%).

There were also several limitations to this study. First of all, this cross-sectional study relied on the memory of orthodontists, which is retrospective and might be less reliable. A limitation of the questionnaire was that no distinction was made in acute allergic reactions and delayed allergic reactions. Most probably a major part of the reported allergic reactions can be considered as local and mild and would not be considered an acute medical emergency. Also, no distinction was made between aspiration within the orthodontic practice and aspiration at home. Another limitation is the closed-ended questions that were used in the questionnaire. Participants' self-perceived competence would be more accurately assessed with open-ended questions that provide them with the possibility to clarify and specify their answers. Furthermore, the situation in the Netherlands may be totally different from other countries, and therefore, the data cannot be extrapolated indiscriminately to other countries.

The most important question that arises from this study is whether the surveyed orthodontists were able to adequately judge their own competence. According to Lai and Teng [28], self-perceived competence does not correlate well with objectively assessed competence, although this assessment was performed in the field of general medicine. Katowa and Banda [29] observed a negative correlation between self-perceived and objectively measured competence, which demonstrates an inability of individuals to assess and rate themselves objectively. It therefore seems that people might over- or underestimate themselves in feeling competent. According to Kruger and Dunning [30], competent people can adequately judge themselves (they slightly underestimate their own performance), while incompetent people frequently overrate their own abilities. They observed that low performing participants greatly overestimated their own abilities. These individuals are especially dangerous in clinical practice and can lead to catastrophic results. One might think to be competent, but simply is unprepared in reality. A major drawback of this study therefore is that competent people were not distinguished from incompetent people, independent of their selfperceived competence. Future research on medical emergencies in orthodontic practice should therefore be based on realistic patient simulation, including the usage of emergency drugs, in which the competence of orthodontists is determined by medical professionals instead of self-perceived abilities. This could give more insight in the actual competence of orthodontists in the Netherlands regarding the management of acute medical emergencies, without the risk of over- and underestimation.

\section{Conclusions}

- Practicing orthodontists in the Netherlands do not frequently encounter medical emergencies in daily practice, with an estimated occurrence of 0.36 acute medical emergencies per orthodontist per year. On average, $75 \%$ of the orthodontists feel competent to handle any acute medical situation.

- In general, health care providers in the Netherlands are obliged to be able to handle acute medical emergencies. It is therefore strongly recommended for all orthodontists and supporting staff to be trained regularly in the management of medical emergencies and keep their evidence-based knowledge up-to-date. Realistic patient-simulation-based training should be part of medical emergency training and annually repeated.

- Familiarity with and availability of appropriate drugs and equipment are deemed essential to the management of acute medical emergencies that may arise in the orthodontic practice.

\section{Supplementary information}

Supplementary information accompanies this paper at https://doi.org/10. 1186/s40510-020-00327-3.

Additional file 1. Questionnaire.

\section{Abbreviations}

AED: Automatic external defibrillator; AP: Angina pectoris; CPR: Cardiopulmonary resuscitation; MI: Myocardial infarct; NVvO: Nederlandse Vereniging van Orthodontisten

\section{Acknowledgements}

The authors would like to thank all orthodontists who participated in the survey and the board of the NVvO for support.

Authors' contributions

$M A B, C L$, and REGJ were all involved in the study design and in writing and revising the manuscript. $M A B$ was responsible for the acquisition and analysis of the data. Finally, all authors read and approved the final manuscript.

Funding

No funding.

Availability of data and materials

The datasets used and/or analyzed during the current study are available from the corresponding author on reasonable request.

Ethics approval and consent to participate Not applicable.

Consent for publication

Not applicable. 


\section{Competing interests}

The authors declare that they have no competing interests.

Received: 21 February 2020 Accepted: 25 June 2020

Published online: 10 August 2020

\section{References}

1. Matsuura $H$. Analysis of systemic complications and deaths during dental treatment in Japan. Anesthesia progress. 1989;36(4-5):223-5.

2. Brand HS. [Problems in your practice]. Nederlands tijdschrift voor tandheelkunde. 2013:120(7-8):363.

3. Vaughan M, Park A, Sholapurkar A, Esterman A. Medical emergencies in dental practice - management requirements and international practitioner proficiency. A scoping review. Australian dental journal. 2018;63(4):455-66.

4. Collange O, Bildstein A, Samin J, Schaeffer R, Mahoudeau G, Feki A, et al. Prevalence of medical emergencies in dental practice. Resuscitation. 2010; 81(7):915-6.

5. Kufta K, Saraghi M, Giannakopoulos H. Cardiovascular considerations for the dental practitioner. 2. Management of cardiac emergencies. General dentistry. 2018;66(1):49-53.

6. Broadbent JM, Thomson WM. The readiness of New Zealand general dental practitioners for medical emergencies. The New Zealand dental journal. 2001;97(429):82-6.

7. de Bedout T, Kramer K, Blanchard S, Hamada Y, Eckert GJ, Maupome G, et al. Assessing the medical emergency preparedness of dental faculty, residents, and practicing periodontists: an exploratory study. Journal of dental education. 2018;82(5):492-500.

8. Turpin DL. Need and demand for orthodontic services: the final report. American journal of orthodontics and dentofacial orthopedics: official publication of the American Association of Orthodontists, its constituent societies, and the American Board of Orthodontics. 2010;137(2):151-152.

9. Kuitert RB. Orthodontic treatment for adults. Nederlands tijdschrift voor tandheelkunde. 2000;107(4):160-8.

10. Little J, Miller C, Rhodus N. Dental management of the medically compromised patient. $9^{\text {th }}$ ed. Mosby; 2017.

11. Stafuzza TC, Carrara CF, Oliveira FV, Santos CF, Oliveira TM. Evaluation of the dentists' knowledge on medical urgency and emergency. Brazilian oral research. 2014;28.

12. Greenwood M. Medical emergencies in dental practice. Primary dental journal. 2014;3(1):4-5.

13. Greenwood M. Medical emergencies: risk assessment and management. Primary dental journal. 2018;7(3):46-56.

14. Anders PL, Comeau RL, Hatton M, Neiders ME. The nature and frequency of medical emergencies among patients in a dental school setting. Journal of dental education. 2010;74(4):392-6.

15. van Diermen DE, van der Waal I, Hoogvliets MW, Ong FN, Hoogstraten J. Survey response of oral and maxillofacial surgeons on invasive procedures in patients using antithrombotic medication. International journal of oral and maxillofacial surgery. 2013;42(4):502-7.

16. Johnson TM, Kurt-Gabel C. Compliance with and attitudes towards the management of medical emergencies in general dental practice. Primary dental journal. 2014;3(1):41-5.

17. Malamed SF. Medical emergencies in dentistry. Refu'at ha-peh vehashinayim (1993). 2002;19(1):6-8

18. Joseph UYAMADU CDO. A review of medical emergencies in dental practice. Orient Journal of Medicine 2012:Vol 24 [3-4](Jul-Dec 2012 ):1-9.

19. Al-Iryani GM, Ali FM, Alnami NH, Almashhur SK, Adawi MA, Tairy AA. Knowledge and preparedness of dental practitioners on management of medical emergencies in Jazan Province. Open access Macedonian journal of medical sciences. 2018:6(2):402-5.

20. KNMT richtlijn patientendossier. https://www.knmt.nl/sites/default/files/1 8006i-herziene_richtlijn-patientendossier-2019.pdf. Accessed on $28^{\text {th }}$ of August 2019.

21. Alhamad M, Alnahwi T, Alshayeb H, Alzayer A, Aldawood O, Almarzouq A, et al. Medical emergencies encountered in dental clinics: a study from the Eastern Province of Saudi Arabia. Journal of family \& community medicine. 2015:22(3):175-9.

22. Arsati F, Montalli VA, Florio FM, Ramacciato JC, da Cunha FL, Cecanho R, et al. Brazilian dentists' attitudes about medical emergencies during dental treatment. Journal of dental education. 2010;74(6):661-6.
23. Haas DA. Management of medical emergencies in the dental office: conditions in each country, the extent of treatment by the dentist. Anesthesia progress. 2006;53(1):20-4.

24. Cukovic-Bagic I, Hrvatin S, Jelicic J, Negovetic Vranic D, Kujundzic Tiljak M, Pezo $\mathrm{H}$, et al. General dentists' awareness of how to cope with medical emergencies in paediatric dental patients. International dental journal. 2017; 67(4):238-43.

25. Marks LA, Van Parys C, Coppens M, Herregods L. Awareness of dental practitioners to cope with a medical emergency: a survey in Belgium. International dental journal. 2013;63(6):312-6.

26. Jevon P. Updated posters to help manage medical emergencies in the dental practice. British dental journal. 2015;219(5):227-9.

27. Kogler L, Seidel EM, Metzler H, Thaler H, Boubela RN, Pruessner JC, et al. Impact of self-esteem and sex on stress reactions. Sci Rep. 7(1):17210.

28. Lai NM, Teng CL. Self-perceived competence correlates poorly with objectively measured competence in evidence based medicine among medical students. BMC medical education. 2011;11:25.

29. Katowa-Mukwato P, Banda S. Self-perceived versus objectively measured competence in performing clinical practical procedures by final year medical students. International journal of medical education. 2016;7:122-9.

30. Kruger J, Dunning D. Unskilled and unaware of it: how difficulties in recognizing one's own incompetence lead to inflated self-assessments. J Pers Soc Psychol. 77(6):1121-1134.

\section{Publisher's Note}

Springer Nature remains neutral with regard to jurisdictional claims in published maps and institutional affiliations.

\section{Submit your manuscript to a SpringerOpen ${ }^{\circ}$ journal and benefit from:}

- Convenient online submission

- Rigorous peer review

- Open access: articles freely available online

- High visibility within the field

- Retaining the copyright to your article

Submit your next manuscript at $\boldsymbol{\nabla}$ springeropen.com 